\title{
PASSAGENS: BENJAMIN, PARIS, BORGES, BUENOS AIRES
}

\author{
Claudio Celso Alano da Cruz ${ }^{1}$
}

RESUMO: A obra Das Passagen-Werk, de Walter Benjamin, que na tradução brasileira recebeu o simples título de Passagens, é o objeto de investigação deste trabalho, central para o que essa pesquisa vem a ser. Tal livro pode ser considerado como um gigantesco arquivo da história social de Paris do século XIX, superando as 1300 páginas na sua edição alemã. $\mathrm{O}$ título deste trabalho corresponde ao do projeto que estou desenvolvendo junto ao CNPq desde março de 2015. O que se apresenta aqui pode ser visto como uma espécie de "carta de intenções", onde busco expor resumidamente tal projeto.

Palavras-chave: Walter Benjamin; Das Passagen-Werk; Passagens; Borges; Buenos Aires.

RESUMEN: La obra Das Passagen-Werk de Walter Benjamin, que en la traducción brasileña ganó el sencillo título de Passagens, es el objeto de este trabajo de investigación, central para lo que se pretende en esta investigación. Este libro puede ser considerado como un gran archivo de la historia social del París del siglo XIX, superior a 1300 páginas en su edición alemana. El título de este trabajo corresponde al proyecto que estoy desarrollando con CNPq desde marzo de 2015. Lo que se presenta aquí se puede ver como una especie de "carta de intenciones", donde busco exponer brevemente tal proyecto.

Palabras clave: Walter Benjamin; Das Passagen-Werk; Passagens; Borges; Buenos Aires.

Obra realmente monumental, Das Passagen-Werk ocupou Benjamin de 1927 até sua morte, em 1940, momento em que alcançava exatos 4234 fragmentos, retirados de 850 livros e distribuídos por 36 arquivos temáticos. Constitui-se como uma das obras críticas mais fecundas e

\footnotetext{
${ }^{1}$ Doutor em Teoria Literária pela Pontifícia Universidade Católica do Rio Grande do Sul (PUCRS), Professor Associado da Universidade Federal de Santa Catarina (UFSC) e Bolsista de Produtividade em Pesquisa do Conselho Nacional de Pesquisa Cientifica (CNPq). Realizou Pós-Doutoramento na Universidad de Buenos Aires (UBA).
} 
instigantes do século XX. Pelo seu inacabamento e modo de composição, o livro tem sido visto como um exemplo cabal e concreto de um conceito essencial para o pensamento de Benjamin, o fragmento, tomado, particularmente nesse livro, como um elemento heurístico. $O$ filósofo alemão operou com ele uma espécie de fusão com o conceito de mônada, de Leibniz. Passagens também pode ser visto, nas palavras de Márcio Seligmann-Silva, como "um gigantesco e potente arquivo" (SELIGMANNSILVA, 2008, p. 100; tradução minha) e, nas de Susan Buck-Morss, como um working lexicon, que nos apresenta uma gama de dados e conhecimentos dos mais ricos e relevantes sobre a história social de Paris, especialmente no período de 1830 a 1871 . Cabe ressaltar que no Instituto de Pesquisa Social, com sede inicial em Frankfurt, ao qual Benjamin se vinculou nos anos de 1930, o seu projeto recebeu o título de The Social History of the City of Paris. Esse dado é relevante porque aquilo estou propondo com esse projeto, entre alguns outros objetivos, é a inserção da obra de Borges, como se verá adiante, no que podemos chamar de "uma pequena história material da Buenos Aires dos anos de 1920".

Apresento a seguir o primeiro desses milhares de fragmentos que constituem o livro das Passagens. Certamente não por acaso, é o primeiro fragmento do primeiro arquivo - o arquivo A -, que se intitula justamente "Passagens". O dito fragmento foi retirado por Benjamin de um Guia Ilustrado de Paris de 1852, e diz assim:

Chamamos repetidamente a atenção (...) às passagens que desembocam nos boulevards internos. Essas passagens, uma recente invenção do luxo industrial, são galerias cobertas de vidro e com paredes revestidas de mármore, que atravessam quarteirões inteiros, e cujos proprietários se uniram para esse tipo de especulação. Em ambos os lados dessas galerias, que recebem sua luz do alto, alinham-se as lojas mais elegantes, de modo que uma tal passagem é uma cidade, um mundo em miniatura (BENJAMIN, 2006, p. 77).

Voltaremos a essa imagem que vê a passagem como um "mundo em miniatura”. Fixemos por agora a idéia de que tais edificações arquitetônicas foram uma autêntica criação parisiense, cuja primeira construção ocorreu em 1799. ${ }^{2}$ Cinquenta anos depois, Paris já contava com cerca de 144

${ }^{2}$ Cf. DELORME, J.C. \& DUBOIS, A.M. Passages couverts parisiens. Paris:Parigramme, 2002. 
passagens, cujos princípios arquitetônicos iriam se propagar pelo mundo, incluindo, claro, Buenos Aires. Em relação ao segundo arquivo de Benjamin - o arquivo B -, todo ele é dedicado à "Moda". $\mathrm{O}$ arquivo $\mathrm{E}$ trata das várias revoluções ocorridas em Paris ao longo do século XIX, intitulando-se "Haussmanização, Lutas de Barricadas". "Construção em ferro" vem a ser o arquivo F. Cito os titulos de alguns outros, no intuito de configurar um panorama maior dos objetivos de Benjamin:

"O Colecionador" forma o arquivo $\mathrm{H}$.

"Baudelaire" corresponde ao arquivo J.

O tema do "Flâneur" constitui o arquivo M.

"Prostituição e Jogo" é o título do arquivo O.

"As ruas de Paris" corresponde ao arquivo $\mathrm{P}$.

"A fotografia" vem a ser o arquivo Y.

E assim sucessivamente.

Cabe aqui a pergunta: o que pretendia Benjamin com tudo isso? Basicamente, e em primeiro lugar, estava buscando entender o atribulado tempo que lhe coube viver. Ou seja, a Europa dos anos de 1930, à beira do caos e da guerra que se avizinhava cada vez mais. E para tanto acreditava ser necessário configurar a pré-história desse mundo moderno. "Cada época sonha a seguinte", dizia o historiador Michelet, em outro fragmento que foi incluído com destaque no livro das Passagens. Benjamin acreditava que mergulhar nos sonhos coletivos do século XIX nos permitiria entender melhor o mundo do século XX. Por um lado apostava nos surrealistas sobretudo Aragon e Breton - , que acreditavam acima de qualquer coisa no conhecimento derivado do inconsciente. Mas, por outro lado, julgava também importante a perspectiva racionalista de Marx e a sua constante preocupação com a consciência. Assim, Benjamin dava uma grande importância tanto ao sonho quanto ao despertar desse sonho. Para realizar essa operação de encontrar no passado o entendimento do presente, Benjamin saiu em busca da experiência política, social e cultural da capital francesa. Especialmente no período que ficou conhecido como o do Segundo Império, que vai do golpe de Estado de Napoleão III, em 1852, até o ano de 1870 , com a derrota na guerra franco-prussiana. Essa foi a época das grandes e radicais transformações urbanas de Paris, empreendidas pelo Barão Haussmann, que ficou conhecido como "o artista demolidor". Responsável maior pelo que se conhece hoje como cidade moderna, ele mandou destruir em grande parte a Paris antiga rasgando-a com largas avenidas - e erguendo em suas praças grandes monumentos. Na verdade, muito mais do que largas avenidas, estavam 
sendo abertos os caminhos para o grande capital especulativo de uma burguesia em sua fase mais exuberante, em plena expansão. Tal era para Benjamin a "Paris, capital do século XIX". A partir dessa experiência histórica da capital francesa é que o filósofo alemão pensou configurar aquela pré-história da Modernidade. Tratava-se, como se vê, de um projeto de considerável complexidade.

No entanto, o livro das Passagens contém um princípio construtivo bastante simples, pelo menos do ponto de vista espacial. Refiro-me àquele devaneio, conhecido de todos, que consiste em se imaginar no centro do mundo e, de maneira crescente, ir abarcando paulatinamente cada região desse vasto universo. Todos nós já brincamos com tal ideia na infância: nossa casa, nossa rua, o bairro, a cidade, até chegarmos aos confins da Via Láctea. Pois não deixa de ser esse, em toda sua singeleza, um dos princípios básicos do livro de Benjamin. Agora voltando: Europa, França, Paris, Bairros, Ruas, Passagens. E bem no centro, no coração das Passagens, Benjamin iria perceber que estava a mercadoria. Só a questão da centralidade absoluta da mercadoria na sociedade moderna em formação, já daria uma pesquisa à parte. ${ }^{3}$ Daí a importância daquele Guia Ilustrado de Paris de 1852, que apresentava a passagem ou galeria como um mundo em miniatura, para onde tudo convergia. Afirma Willi Bolle, o organizador da edição brasileira das Passagens:

Inspirado nas obras dos escritores surrealistas, sobretudo $O$ camponês de Paris (1926), de Louis Aragon, o crítico descobre como núcleo da metrópole moderna as 'passagens' ou galerias de compras criadas em Paris a partir do início do século XIX e inseridas em uma economia de mercado "global", com formas de comportamento marcadas pela mentalidade do lucro e do consumo (BOLLE, 2008, p. 26; tradução minha).

Sabe-se que nenhuma metrópole no mundo ficou imune aos encantos daquela "Paris, capital do século XIX". Buenos Aires, particularmente, viu-se enfeitiçada por tais encantos, e também construiu as suas passagens. Em seguida voltaremos a essa cidade. Antes disso, caberia

\footnotetext{
${ }^{3}$ Pesquisa que começaria, naturalmente, pelo primeiro capitulo de O capital, de Karl Marx, onde o autor desenvolve o hoje célebre conceito do fetichismo da mercadoria, central para Benjamin nas Passagens.
} 
lembrar que o mesmo Willi Bolle, utilizando-se do livro das Passagens para pensar a questão da modernidade desde a perspectiva de uma metrópole periférica como São Paulo, defende a ideia que

[d]eterminadas observações e reflexões em seus escritos esperam por ser 'arrancadas de seu contexto', de um ponto de vista diferente do europeu, para serem montadas segundo uma nova planta de construção (idem, 1994. p. 28).

Márcio Seligmann-Silva reitera essas ideias:

Benjamin não só reconstitui o século XIX a partir das passagens parisienses, mas cria um modelo de leitura/escritura que pode servir para muitas outras épocas (SELIGMANN-SILVA, 2008, p. 103).

E logo adiante completa:

Cabe a cada leitor executar essa obra-partitura. Aprender a ler, a desmontar para remontar as Passagens. Essa obra de Benjamin já nasceu destinada a ser este projeto, uma obra em movimento. É processo, passagem constante. Trata-se de uma obra líquida. Maleável (idem, ibidem).

Difícil saber até que ponto ideias como as apresentadas acima estariam nos planos de Benjamin, mas isso é o que menos importa. Sua própria concepção de história, que dá primazia absoluta ao momento presente e, portanto, a uma leitura contemporânea, corrobora e abre caminho a tais ideias. Enfim, se quisermos ser verdadeiramente fiéis a ele, devemos lê-lo na perspectiva de hoje, do "tempo-do-agora, do Jetztzeit, como ele denominava o tempo em que o crítico deveria estar "imerso", além de "desperto". Aliás, essa concepção de Benjamin afina-se perfeitamente com aquela de Borges que, numa certa perspectiva, ia ainda mais longe. Para ele, esse era o único ponto de vista de que dispúnhamos, o ponto de vista nosso contemporâneo, quiséssemos ou não. E como afirmou inúmeras vezes, se fosse possivel a nós saber o modo de ler em um mundo futuro, saberíamos o essencial a respeito desse mundo.

Pois bem, se é verdade, como dizia ainda Borges, que a melhor forma de ler um livro é reescrevê-lo, reescrever o livro das Passagens talvez 
seja a melhor forma de fazer jus a ele. Claro que, dado o seu desmesurado volume, mas principalmente sua complexidade, conviria tomar uma série de precauções, além de estabelecer limites precisos, qualquer que seja a nossa re-escritura. O certo é que, dada a riqueza de seus fragmentos, fruto de quinze anos de incansáveis pesquisas, fichamentos e escrituras, Passagens incita-nos a imaginar e criar a nossa própria operação de montagem, conforme propõem os comentadores citados. Na verdade, o livro de Benjamin sugere muito mais, sugere-nos mesmo a possibilidade de irmos além, criando arquivos temáticos originais, colecionando e reunindo fragmentos escolhidos por nós próprios, em função do nosso objeto e objetivo de pesquisa, abrindo perspectivas para outras e variadas montagens. Foi a partir dessas reflexões que me ocorreu a ideia de imaginar uma "passagem" entre a "central" Paris de Benjamin e a "periférica" Buenos Aires de Borges, a fim de constituir um arquivo temático para a capital argentina à semelhança, principalmente do ponto de vista metodológico, daquele concebido por Benjamin para Paris. Somente que agora restringindo-se a um âmbito estritamente literário, e focando num contexto histórico bem mais reduzido: Buenos Aires, década de 1920. Para melhor me fazer entender, passo agora a expor alguns dados sobre a capital argentina.

Começo por lembrar que, do lado de cá do Atlântico, Buenos Aires também seria palco de uma das experiências de modernização das mais ricas ocorridas em países periféricos. Claro que de um modo defasado e precário, próprio da América Latina em relação à Europa. Tal modernização ganharia impulso a partir de 1880, quando Buenos Aires alcançou o status de Capital Federal. Tinha início o chamado período liberal-democrático que só se encerraria cinquenta anos depois com o golpe militar de Uriburu, em 1930. A Argentina era então uma nação que se via - e desejava ardentemente ser vista - como uma parceira "muito especial" das potências da época: França e Inglaterra. Sua capital, Buenos Aires, vivia o sonho de ser a "Paris da América do Sul". Tal experiência histórica pode ser vista como um dos exemplos cabais do que se passou a chamar de "modernidade tardia”, com todas as suas típicas contradições, fantasmagorias e ilusões. ${ }^{4}$

\footnotetext{
${ }^{4}$ Esse periodo de modernização da Argentina e, em particular, de Buenos Aires, tem sido bastante investigado, estando disponivel uma já considerável bibliografia. A grande e primeira referência, no entanto, continua sendo SCOBIE, James. Buenos Aires. Plaza to suburbs, 1870 . 1910, Oxford University Press, 1974. Para o periodo imediatamente posterior, e já mais voltado para uma perspectiva literária e cultural, caberia citar SARLO, Beatriz. Una modernidad periférica. Buenos Aires 1920 y 1930. Buenos Aires: Nueva Visión, 1988.
} 
Mas também - e apesar de tudo - com grandes e definitivas conquistas. Uma delas viria a ser a própria literatura de Borges, autor que, numa inversão inédita na história da literatura, acabaria se estabelecendo como um verdadeiro mestre para os escritores europeus. ${ }^{5}$ Assim, quando se pensa na escolha de um escritor representativo de todo esse processo, é Borges que surge no horizonte em primeiro lugar. Mas se é possivel estabelecer analogias entre as duas experiências históricas - a de Paris e a de Buenos Aires - torna-se necessário também apontar para diferenças marcantes que devem ser levadas em consideração. Tal operação deve ser feita se quisermos "aclimatar" adequada e produtivamente a teoria de Benjamin a terras americanas. Vamos então definir, em linhas bem gerais, o modo pelo qual esse diálogo entre o livro das Passagens e a obra de Borges dos anos de 1920 deverá ir se acomodando no âmbito espacial e temporal.

Em relação ao espaço, o foco será Buenos Aires, mas dando-se uma atenção maior à periferia da cidade, ou seja, ao seu arrabal. O hoje tão conhecido flâneur de Benjamin circulava, principalmente, pelo centro de Paris, pelas suas avenidas ou bulevares mais elegantes. Isso não significa que não iremos encontrar nas Passagens, também, fragmentos relativos às margens da metrópole, a seu lado "menos nobre", como podemos ler no seguinte fragmento selecionado por Benjamin:

O poeta Musset denominou certa vez o trecho dos bulevares que se localiza atrás do Teatro de Variedades - e que não era frequentado pelos flâneurs - de "grandes Indias" (BENJAMIN, 2006, p. 471).

... "grandes Índias" significando aqui algo próximo às "colônias europeias do mundo", ou mesmo, mais brutalmente falando, "o resto do mundo". Trata-se de um fragmento notável para o que nos interessa, ao mesmo tempo em que nos leva para um determinado caminho investigativo do livro das Passagens. Conforme ainda Willi Bolle, Benjamin evoca nessa citação sobre Musset

[o] território de aproximadamente uma légua que rodeia a cidade, sobre o qual se estendia a exclusão a que são

\footnotetext{
${ }^{5}$ O momento paradigmático a respeito, como se sabe, ocorre em 1966, quando Michel Foucault abre o seu clássico As palavras e as coisas, que ficaria como uma das obras filosóficas mais importantes do século XX, afirmando com todas as letras: "Este livro nasceu de um texto de Borges".
} 
relegadas as "massas escuras" (...), que não conseguiram obter um lugar no cenário da capital do Imperio. Assim, a pouca distância dos lugares de encontro e ostentação da burguesia, já começava, na periferia de Paris, a periferia do mundo (BOLLE, 2008, p. 37).

Em relação ao tempo, quer-se destacar o final desse processo de modernização de Buenos Aires. Ou seja, a década de 1920, quando o jovem Borges iria despontar como um dos críticos mais agudos dessas ilusões, ficando de costas para aquela suposta "Paris sul-americana". Buscará na periferia da metrópole uma Argentina mais autêntica e criolla. Tal veio a ser o solo histórico, social e cultural para a criação da sua conhecida "mitologia do subúrbio" ${ }^{6}$. Neste ponto da apresentação, caberia exemplificar, um pouco mais detalhadamente, pelo menos um desses arquivos. Escolho o arquivo $\mathrm{G}$, que irá no meu trabalho corresponder muito de perto ao arquivo $\mathrm{A}$ do livro de Benjamin, aquele referente às passagens parisienses, como já visto no início. Reservei tal arquivo G para essa verdadeira instituição portenha que vem a ser o almacén. Trata-se do que podemos chamar de uma "arquitetura menor", se a compararmos com as passagens ou galerias comerciais. Nem por isso deixou de ser, para a zona periférica de Buenos Aires, um equipamento urbano dos mais importantes, já que se estabeleceu como um núcleo fundamental das sociabilidades suburbanas. ${ }^{7}$ Assim, operando por deslizamento, buscarei estabelecer possíveis analogias entre o almacén e a passagem ou galeria comercial. Tal como ocorria com as passagens na zona central, para lugares como os almacéns convergia toda a população dos bairros portenhos. Os almacéns eram, além de locais de comércio, pontos de encontro, de troca de informações, de jogos, divertimentos, comemorações, e uma série de outras atividades que ocupavam as pessoas no seu dia-a-dia. Ou seja, guardadas as devidas diferenças socioculturais, tal almacén parece apontar para não poucas semelhanças com as passagens. Assim, da perspectiva do Borges que buscava criar uma "mitologia do subúrbio", esse almacén poderia vir a representar para esse subúrbio - em alguma medida - papel semelhante ao

\footnotetext{
${ }^{6}$ Sobre a formação desse subúrbio portenho na perspectiva borgeana e as origens históricas de sua principal figura, o compadrito, ver: CRUZ, Claudio Celso Alano da. Contribuição para uma arqueologia do compadrito borgeano. In: Variaciones Borges, Pittsburgh:University of Pittsburgh, v. 31, 2011.

${ }^{7}$ Ver a respeito, especialmente: GAYOL, Sandra. Sociabilidades en Buenos Aires: hombres, honor y cafés (1862-1910). Buenos Aires:Ediciones del Signo, 2007.
} 
que as passagens representavam para as zonas centrais das metrópoles. Se pensarmos a partir dessa ótica borgeana, mais adequado seria dizer: em contraposição às passagens das zonas centrais. Isso porque Borges demonstrava um enorme ceticismo em relação a qualquer "modernolatria" ou "ideologia do progresso", ideias muito vinculadas, naturalmente, às passagens ou galerias. Daí a sua "fuga" para regiões periféricas da metrópole naquele momento. As zonas marginais da cidade se mostravam bem mais resistentes, segundo ele, a tais ilusões. Concluo aqui essas rápidas palavras sobre o arquivo $G$ e passo a elencar alguns outros, buscando dar uma ideia melhor do que pretendo.

Assim, o meu arquivo A foi pensado para reunir materiais ligados às origens e ao estabelecimento histórico do subúrbio portenho em geral. $\mathrm{O}$ arquivo $\mathrm{F}$ será todo dedicado ao tango, a maior expressão cultural da Argentina. $\mathrm{O}$ arquivo $\mathrm{P}$ visa refletir sobre essa Buenos Aires vista como "a Paris da América do Sul”. Reservei o arquivo h para todo o complexo processo de construção de Puerto Madero, fator decisivo para a modernização e expansão da capital argentina. $\mathrm{O}$ arquivo $Q$ ficou para as calles de Buenos Aires. Outros arquivos foram reservados para temas como a imigração e a prostituição, que marcaram forte presença em Buenos Aires na época. Também o bairro de Palermo, onde Borges passou a infância, constitui outro pólo temático significativo, incluindo aí os compadritos e seu "culto à coragem", que seriam imortalizados pela literatura borgeana. Poderia citar ainda o processo de construção do Metrô de Buenos Aires, do Jardim Botânico e do Zoológico (onde Borges iria conhecer na infância o tigre que o acompanharia pelo resto da sua vida), e assim sucessivamente.

Dessa forma, tomando como eixo a obra inicial de Borges, o que se pretende é realizar um "mergulho" nesse período histórico de Buenos Aires, em todos os sentidos: econômico, político, social e cultural. Trata-se de pensar a obra de Borges na década de 1920 e a década de 1920 na obra de Borges. E, de forma muito particular, pensar o ambiente sócio-cultural do arrabal, já que foi o espaço privilegiado por Borges em toda aquela década. A essa altura, acredito que já se pode enunciar o Objetivo Fundamental desse projeto que acabo de expor sinteticamente, qual seja: elaborar um Arquivo Temático Piloto - tomando como modelo o livro das Passagens - para estabelecer as bases de uma análise materialista e dialética da vertente criolla de Borges em seu contexto fundacional: Buenos Aires, década de 1920.

Para concluir essa exposição, transcrevo abaixo, seguindo a edição brasileira do livro das Passagens, a relação dos 36 arquivos temáticos de Benjamin, incluidos na seção Notas e Materiais, que constitui o essencial 
da obra. E, na sequência, transcrevo também os 36 arquivos correspondentes ao que estou chamando aqui de Arquivo Temático Piloto que, naturalmente, deverá sofrer modificações e adaptações ao longo da pesquisa, mas que dá uma idéia aproximada do que se pretende.

\section{BENJAMIN-PARIS}

Arquivos A- Z:

A - Passagens, Magasins de nouveautés, Calicots

B - Moda

C - Paris Antiga, Catacumbas, Demolições, Declínio de Paris

D - O Tédio, Eterno Retorno

E - Haussmannização, Lutas de Barricadas

F - Construção em Ferro

$\mathrm{G}$ - Exposições, Reclame, Grandville

$\mathrm{H}$ - O Colecionador

I - O Intérieur, o Rastro

$\mathrm{J}$ - Baudelaire

K - Cidade de Sonho e Morada de Sonho, Sonhos de Futuro, Niilismo, Jung

L - Morada de Sonho, Museu, Pavilhão Termal

M - O Flâneur

N - Teoria do Conhecimento, Teoria do Progresso

O - Prostituição, Jogo

$\mathrm{P}$ - As Ruas de Paris

Q - Panorama

R - Espelhos

S - Pintura, Jugendstil, Novidade

$\mathrm{T}$ - Tipos de Iluminação

U - Saint-Simon, Ferrovias

V - Conspirações, Compagnonnage

W- Fourier

$X-$ Marx

Y - A Fotografia

Z - A Boneca, o Autômato

Arquivos $a-z$ :

a - Movimento Social

b - Daumier 
d - História Literária, Hugo

g - A Bolsa de Valores, História Econômica

i - Técnica de Reprodução, Litografia

$\mathrm{k}$ - A Comuna

1 - O Sena, A Paris Mais Antiga

m - Ócio e Ociosidade

p - Materialismo Antropológico, História das Seitas

r - École Polytechnique

\section{BORGES-BUENOS AIRES}

Arquivos A $-\mathrm{Z}$ :

A - Arrabal

B - Borges

C - Compadrito, Culto à coragem

D - Duelo, Punhal

E - Carriego

F - Tango, Gardel

G - Almacén, Cafés

H - Conventillos, Aluvião imigratório

I - Comitê Eleitoral, Lei Saenz-Peña

J - Prostituição, "La mala vida"

K - Bairro de Palermo, Arroio Maldonado

L - Sainete, Lunfardo

M - La Boca, Riachuelo

$\mathrm{N}$ - Benjamin, Imagem dialética

O - Hipólito Yrigoyen

P - Centenário: Paris é aqui.

Q - Calles de Buenos Aires

R - Lugones, Macedonio, Güiraldes

$S$ - Metrô, Ferrocarriles

$\mathrm{T}$ - Jardim Botânico, Zoológico

U - Polêmica Boedo x Florida

V - Mercado Literário, Imprensa, Revistas

$\mathrm{X}$ - Semana Trágica, Anarquismo, Socialismo

Y - Gauchesca, Martín Fierro

Z - Sarmiento, Século XIX

arquivos $\mathbf{a}-z$ : 
a - Barrio Norte, formação do

b - Febre amarela

c - Geração de 80

d - Conquista do Deserto, Gal. Roca

e - Roberto Arlt, Aguafuertes portenhas

f - Avenida de Mayo, bulevares

g - Ricardo Güiraldes, adeus ao Pampa

i - Calle Florida, uma "passagem" a céu aberto

\section{REFERÊNCIAS:}

BENJAMIN, Walter. Passagens. Organização: Willi Bolle. Colaboração: Olgária Chain Féres Matos. São Paulo/Belo Horizonte: Imprensa Oficial/Ed.UFMG, 2006.

. Charles Baudelaire, um lírico no auge do capitalismo. São Paulo: Brasiliense, 1989. Obras escolhidas III.

BOLLE, Willi. Fisiognomia da metrópole moderna. Representação da história em Walter Benjamin. São Paulo:Edusp/Fapesp, 1994.

. Pasajes, de Walter Benjamin. In: VEDDA, Miguel (Org.). Walter Benjamin, constelaciones dialécticas. Buenos Aires: Herramienta, 2008.

BORGES, Jorge Luis. Obras completas. Buenos Aires: Emecé, 1974. . Inquisiciones. Buenos Aires. Buenos Aires: Seix Barral, 1994. . El tamaño de mi esperanza. Buenos Aires: Seix Barral, 1993. . El idioma de los argentinos. Madrid: Alianza, 2002. . Textos recobrados (1919-1929). Buenos Aires: Emecé, 1997.

DELORME, J.C. \& DUBOIS, A.M. Passages couverts parisiens. Paris: Parigramme, 2002. 
GAYOL, Sandra. Sociabilidades en Buenos Aires: hombres, honor y cafés (1862-1910). Buenos Aires: Ediciones del Signo, 2007.

SARLO, Beatriz. Una modernidad periférica. Buenos Aires, 1920 y 1930. Buenos Aires: Nueva Visión, 1988.

SCOBIE, James. Buenos Aires, del centro a los barrios (1870-1910). Buenos Aires: Solar-Hachette, 1977.

SELIGMANN-SILVA, Márcio. Cuando la teoría reencuentra el campo visual. Los Pasajes de Walter Benjamin. In: VEDDA, Miguel (Org.). Walter Benjamin, constelaciones dialécticas. Buenos Aires: Herramienta, 2008.

VEDDA, Miguel (Org.). Walter Benjamin, constelaciones dialécticas. Buenos Aires: Herramienta, 2008.

Recebido em: 11/05/2016

Aceito em: 01/07/2016 